\title{
Effect of Cu Incorporation on Structure, Densification and Magnetic Properties of Polycrystalline $\mathrm{Li}_{x} \mathrm{Ni}_{0.2} \mathrm{Zn}_{0.8-2 x} \mathrm{Fe}_{2+x} \mathrm{O}_{4}$ Ceramics
}

\author{
Halima Akter Liya', Ruhina Akter¹, Abdul Ahad', M. N. I. Khan'2, M. J. Miah" \\ ${ }^{1}$ Department of Physics, Comilla University, Cumilla, Bangladesh \\ ${ }^{2}$ Materials Science Division, Bangladesh Atomic Energy Commission, Dhaka, Bangladesh \\ Email: *mmjulhash@yahoo.com
}

How to cite this paper: Liya, H.A., Akter, R., Ahad, A., Khan, M.N.I. and Miah, M.J. (2021) Effect of $\mathrm{Cu}$ Incorporation on Structure, Densification and Magnetic Properties of Polycrystalline $\mathrm{Li}_{x} \mathrm{Ni}_{0.2} \mathrm{Zn}_{0.8-2 x} \mathrm{Fe}_{2+x} \mathrm{O}_{4}$ Ceramics. Journal of Applied Mathematics and Physics, 9, 3211-3229.

https://doi.org/10.4236/jamp.2021.912210

Received: October 27, 2021

Accepted: December 28, 2021

Published: December 31, 2021

Copyright $\odot 2021$ by author(s) and Scientific Research Publishing Inc. This work is licensed under the Creative Commons Attribution International License (CC BY 4.0).

http://creativecommons.org/licenses/by/4.0/

\begin{abstract}
The polycrystalline $\mathrm{Li}_{x} \mathrm{Ni}_{0.2} \mathrm{Zn}_{0.8-2 x} \mathrm{Fe}_{x+2} \mathrm{O}_{4}$ and $\mathrm{Li}_{x} \mathrm{Ni}_{0.1} \mathrm{Cu}_{0.1} \mathrm{Zn}_{0.8-2 . x} \mathrm{Fe}_{x+2} \mathrm{O}_{4}(x=$ $0.0,0.1,0.2$, and 0.3$)$ ferrites were synthesized by the standard solid-state reaction method. The compound was sintered at $1150^{\circ} \mathrm{C}$ for 5 hours. The effect of $\mathrm{Cu}$ substitution and its impact on the crystal structure, microstructure, complex initial permeability and magnetization of the Ni-Zn ferrites were studied. The effect of $\mathrm{Li}^{+}$incorporation on the properties mentioned above was also investigated. X-ray diffraction patterns of the samples indicated a single cubic spinel structure for both the compound. No effect of $\mathrm{Cu}$ addition on crystal structure was observed. The density of the ferrites was found to be enhanced because of adding Li whereas the porosity of the samples decreased with the content of Li ions. The average value of grain size increased with the addition of $\mathrm{Li}$ content. The samples having $\mathrm{Cu}$ ions formed bigger size grains. Frequency-dependent complex initial permeability, loss tangent, and relative quality factor were studied at room temperature using an Impedance analyzer in the range of $100 \mathrm{~Hz}-120 \mathrm{MHz}$ regions. In the low-frequency region, the prepared samples exhibited a high value of permeability and after a certain frequency, the permeability falls. The value of permeability enhanced with the increase in $\mathrm{Li}$ whereas loss tangent was found to be reduced. The relative quality factor graphs described that the compound has excellent frequency stability up to a certain frequency which is suitable to be used in inductors, resistors, capacitors, etc. Initial permeability for $\mathrm{Li}_{x} \mathrm{Ni}_{0.1} \mathrm{Cu}_{0.1} \mathrm{Zn}_{0.8-2 x} \mathrm{Fe}_{x+2} \mathrm{O}_{4}$ ferrites was found high than $\mathrm{Li}_{x} \mathrm{Ni}_{0.2} \mathrm{Zn}_{0.8-2 x} \mathrm{Fe}_{x+2} \mathrm{O}_{4}$ which might be attributed to having bigger size grains of $\mathrm{Cu}$ containing samples because of easy movement of domain wall in bigger size grains. The values of saturation magnetization $\left(M_{s}\right)$ were calculated for both compounds from $\mathrm{M}-\mathrm{H}$ hysteresis loops and it enhanced with the increase in $\mathrm{Li}$ content which might be related to the
\end{abstract}


modification of predominant exchange interactions between the cations. The $\mathrm{Cu}$-containing compound exhibited higher values of saturation magnetization. The cation distribution reflects this increment because ferromagnetic $\mathrm{Ni}^{2+}$ and paramagnetic $\mathrm{Cu}^{2+}$ ions occupied in the B-sites and the diamagnetic $\mathrm{Zn}$ and paramagnetic Li occupied in the A-sites; therefore, net magnetic moments increased gradually. The studied materials might be used as an alternative to $\mathrm{Pb}$-based compounds and would be environment friendly.

\section{Keywords}

Ceramics, Ferrites, Complex Initial Permeability, Saturation Magnetization

\section{Introduction}

The demand for magnetic ceramics in the modern technological world is increasing day by day because of their versatile contribution to the miniaturization of many electrical devices. Ferrites are an important class of magnetic ceramics that are composed of iron oxides and other metallic ions. They are non-conducting magnetic compounds. The general chemical formulae of ferrites are $\mathrm{MeFe}_{2} \mathrm{O}_{3}$, where $M$ stands for suitable divalent metal ions such as $\mathrm{Co}^{2+}, \mathrm{Mn}^{2+}, \mathrm{Ni}^{2+}, \mathrm{Fe}^{2+}$, $\mathrm{Zn}^{2+}, \mathrm{Cd}^{2+}, \mathrm{Mg}^{2+}$, etc. and $\mathrm{Fe}$ is the trivalent ferric ion. Based on crystal structure, ferrites are of four types: spinel, garnet, ortho, and hexagonal. Depending upon the magnetic properties they might be soft ferrites and hard ferrites. The spinel soft ferrites have high demand because of their highest possible number of symmetries [1] [2] [3]. In research, it gained a lot of interest because of its low price and easy magnetizing and demagnetizing properties. X-ray crystallography described that the spinel ferrites have a face-centered cubic structure where oxygen ions are packed closely together with the much smaller divalent and trivalent metal ions in the interstitial sites. There are two types of interstitial sites. If the interstitial sites are denoted by A- and B- respectively, then there are 64Aand $32 \mathrm{~B}$-sites in the unit cell of the structure. Considering the substitution atoms in A-site and B-site the spinel ferrites can exhibit ferrimagnetic, antiferromagnetic, and paramagnetic behavior [4].

The cubic structured soft ferrite $\mathrm{Ni}-\mathrm{Zn}$ possesses good magnetic and electric properties and there is much research is going on to improve their properties. The Ni-Zn ferrites have potential applications in antenna rods, loading coils and core materials for power transformations in electronics and telecommunications. Nowadays, a large number of researchers are working on $\mathrm{Ni}-\mathrm{Cu}-\mathrm{Zn}$ ferrites because $\mathrm{Ni}-\mathrm{Zn}$ ferrites create cation vacancies, unsaturated oxygen ions and excessive electrons due to the loss of $\mathrm{Zn}$ during the calcination and sintering process [5]. These unwanted problems are reduced by the substitution of nonmagnetic metal ions (such as $\mathrm{Cu}$ ) in $\mathrm{Ni}-\mathrm{Zn}$ ferrites. The substitution of magnetic ion $\mathrm{Ni}$ by the $\mathrm{Cu}$ modifies the cation distribution process in the system and plays an important role to enhance various properties of $\mathrm{Ni}-\mathrm{Cu}-\mathrm{Zn}$ ferrites [6]-[11]. The 
$\mathrm{Ni}-\mathrm{Cu}-\mathrm{Zn}$ ferrites have various excellent properties such as high resistivity, low cost and low sintering temperature. They are used for multilayer chip inductors and electromagnetic interference (EMI) filters. Li substitution in place of $\mathrm{Zn}$ in $\mathrm{Ni}-\mathrm{Zn}$ ferrites is also emerging research because of their high demand in industrial and technological applications. Research on $\mathrm{Li}$ substitution in $\mathrm{Ni}-\mathrm{Cu}-\mathrm{Zn}$ ferrites requires more study because a small number of foreign ions in the ferrite can dramatically change its properties. $\mathrm{Li}$ and $\mathrm{Li}$ substituted ferrites are performed as an excellent material in high-density recording media and absorbers and microwave devices because of their low cost, high saturation magnetization, high Curie temperature, etc. [12]-[17]. They exhibit comparatively better performances over other spinel ferrites. Detailed studies of the effect of $\mathrm{Cu}^{2+}$ incorporation on structure, density, microstructure, complex initial permeability, and magnetization of Li doped $\mathrm{Ni}-\mathrm{Zn}$ ferrites have been reported here.

\section{Experimental Details}

\subsection{Synthesis}

The polycrystalline $\mathrm{Li}_{x} \mathrm{Ni}_{0.2} \mathrm{Zn}_{0.8-2 . x} \mathrm{Fe}_{x+2} \mathrm{O}_{4}$ and $\mathrm{Li}_{x} \mathrm{Ni}_{0.1} \mathrm{Cu}_{0.1} \mathrm{Zn}_{0.8-2 . x} \mathrm{Fe}_{x+2} \mathrm{O}_{4}(x=0.0$, $0.1,0.2$, and 0.3 ) ferrites were synthesized following the conventional solid-state reaction method from the raw materials of $\mathrm{Li}_{2} \mathrm{O}_{3}(99.9 \%), \mathrm{Ni}_{2} \mathrm{O}_{3}(99.9 \%), \mathrm{CuO}$ (99.99\%), $\mathrm{ZnO}$ (99.9\%) and $\mathrm{Fe}_{2} \mathrm{O}_{3}$ (99.9\%). The raw powders were mixed with acetone by a mortar and pestle. To obtain a homogeneous mixture the mixed powders were blended for $6 \mathrm{~h}$ and then calcined at $850^{\circ} \mathrm{C}$ for $5 \mathrm{~h}$. The powders were blended again for $2 \mathrm{~h}$. One drop of polyvinyl alcohol was added with the mixed powders as a binder for sample preparation. Then toroid- and disc-shaped samples were prepared using a hydraulic press. Finally, the prepared samples were sintered at $1150^{\circ} \mathrm{C}$ for $5 \mathrm{~h}$.

\subsection{Characterization}

X-ray diffractometer (Philips PANalytical X'PERT-PRO) with $\mathrm{CuK}_{\alpha}$ radiation ( $\lambda$ $=1.541 \AA$ ) was used to study the crystal structure of the sintered samples. The lattice parameter $(a)$ was calculated using the following relation:

$$
d^{2}=\frac{a^{2}}{h^{2}+k^{2}+l^{2}}
$$

where $h, k$, and $l$ are the Miller indices and $d$ is the interplanar distance. The exact value of $a$ was calculated using the Nelson-Riley function:

$$
F(\theta)=\frac{1}{2}\left(\frac{\cos ^{2} \theta}{\sin \theta}+\frac{\cos ^{2} \theta}{\theta}\right)
$$

where $\theta$ is the Bragg angle. A straight-line fit was achieved and the exact value of $a$ was obtained from the extrapolation of these lines to $F(\theta)=0$.

Theoretical density $\left(\rho_{t h}\right)$ was calculated using the following formula:

$$
\rho_{t h}=\frac{Z M}{N_{A} a^{3}}
$$


where $Z$ is the number of atoms per unit cell, $M$ is the molecular mass of the sample, and $N_{A}$ is Avogadro's number. The bulk density ( $\rho_{B}$ ) of the sintered samples was calculated using the following equation:

$$
\rho_{B}=\frac{m}{\pi r^{2} t}
$$

where $m$ is the mass, $r$ is the radius and $t$ is the thickness of the sample. The porosity $(P)$ of the samples was determined using the following relation:

$$
P=\frac{\rho_{t h}-\rho_{B}}{\rho_{t h}} \times 100 \%
$$

To study the microstructural analysis Scanning Electron Microscopy (SEM) was used. The average grain diameter $(\bar{D})$ was determined using the Image $J$ software. Wayne Kerr Impedance Analyzer (model: Wayne Kerr 6500B) was used to analyze the $\mu_{i}^{\prime}$. The following equation was used to calculate the $\mu_{i}^{\prime}$.

$$
\mu_{i}^{\prime}=\frac{L_{s}}{L_{0}}
$$

where $L_{s}$ is the inductance of the sample and $L_{0}=\frac{\mu_{0} N^{2} S}{\pi d}$ is the inductance of the winding coil without the sample, where $N$ represents the number of turns of coil $(N=4), S$ is the area of cross-sectional area and $d\left(=\frac{d_{i}+d_{0}}{2}\right)$ is the mean diameter of the sample. The relative quality factor (RQF) was calculated using the following equation:

$$
\mathrm{RQF}=\frac{\mu_{i}^{\prime}}{\tan \delta_{M}}
$$

where $\tan \delta$ is the magnetic loss.

A Vibrating Sample Magnetometer (VSM) was used to measure the $M$ - $H$ hysteresis loop and magnetization, coercivity, etc. of the materials were determined from the hysteresis loop.

\section{Results and Discussion}

\subsection{Crystal Structure}

Figure 1(a) and Figure 1(b) show the XRD pattern of various $\mathrm{Li}_{x} \mathrm{Ni}_{0.2} \mathrm{Zn}_{0.8-2 x} \mathrm{Fe}_{x+2} \mathrm{O}_{4}$ $(x=0.0,0.1,0.2$ and 0.3$)$ and $\mathrm{Li}_{x} \mathrm{Ni}_{0.1} \mathrm{Cu}_{0.1} \mathrm{Zn}_{0.8-2 .} \mathrm{Fe}_{2+x} \mathrm{O}_{4},(x=0.0,0.1,0.2,0.3)$ ferrites. Narrow and clear peak of different planes are observed in the XRD pattern which suggest good crystallinity of the prepared samples. The peaks of the XRD pattern are indexed following previously published articles [18].

It is seen that the high index peaks are shifting to the right-hand side with the substitution of $\mathrm{Li}$ content and this tendency is clearly noticed in both XRD patterns. The shifting of the peaks to the right-hand side suggests shrinkage of the unit cell volume of the compound. It is found that the XRD pattern matched with the XRD pattern of $\mathrm{Ni}-\mathrm{Zn}$ type ferrites which indicates that the prepared 

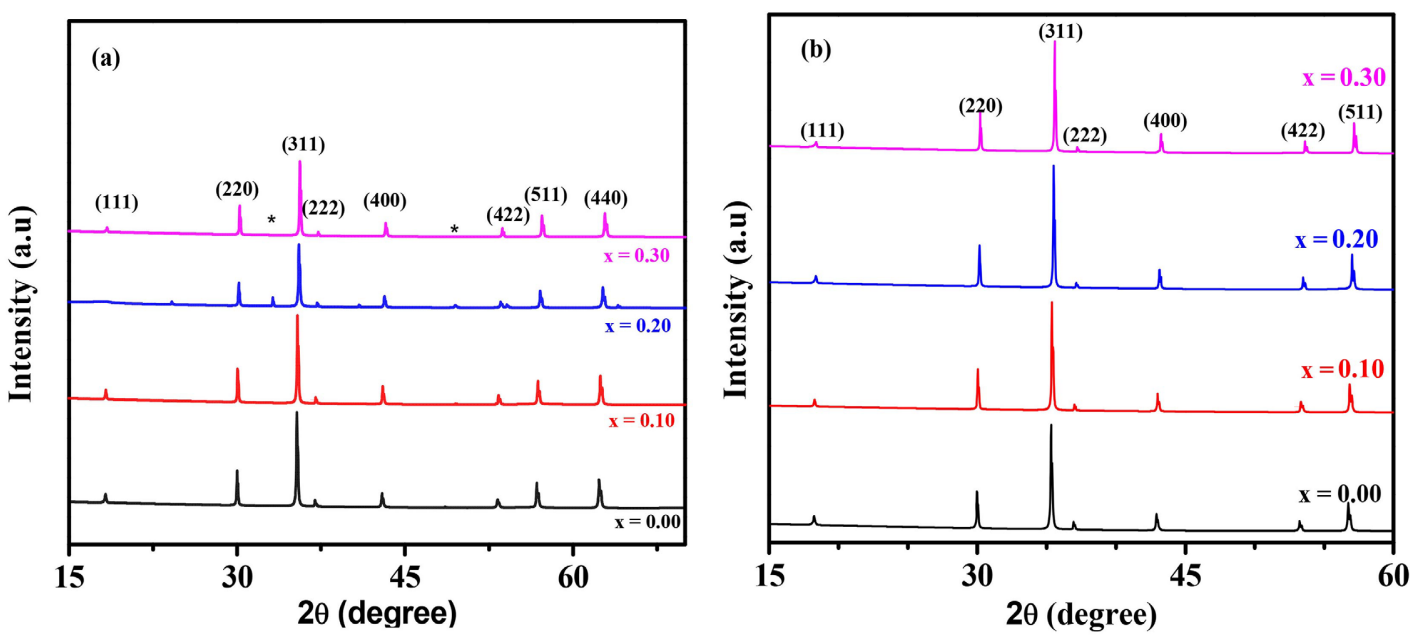

Figure 1. XRD pattern of various (a) $\mathrm{Li}_{x} \mathrm{Ni}_{0.2} \mathrm{Zn}_{0.8-2 x} \mathrm{Fe}_{x+2} \mathrm{O}_{4}$ and (b) $\mathrm{Li}_{x} \mathrm{Ni}_{0.1} \mathrm{Cu}_{0.1} \mathrm{Zn}_{0.8-2 x} \mathrm{Fe}_{2+x} \mathrm{O}_{4},(x=0.0,0.1,0.2$, 0.3 ) ferrites sintered at $1150^{\circ} \mathrm{C}$ temperature.

samples have cubic spinal structure. The lattice constant for each sample is determined using the formula of cubic crystal structure. The values of lattice constants corresponding to all peaks for an individual sample are plotted against the Nelson-Riley function $F(\theta)$ [19]. The Nelson-Riley function can be written as,

$$
F(\theta)=\frac{1}{2} \frac{\cos ^{2} \theta}{\sin \theta}+\frac{\cos ^{2} \theta}{\theta}
$$

where $\theta$ is Bragg's angle. The relation between $F(\theta)$ and lattice constant of $\mathrm{Li}_{x-}$ $\mathrm{Ni}_{0.2} \mathrm{Zn}_{0.8-2 x} \mathrm{Fe}_{x+2} \mathrm{O}_{4}$ ferrites has been shown in Figure 2. The accurate value of lattice constant for a single sample is estimated from the extrapolation of the fitted lines to the y-axis. Values of lattice constant for different amount of Li content compound of $\mathrm{Li}_{x} \mathrm{Ni}_{0.2} \mathrm{Zn}_{0.8-2 . x} \mathrm{Fe}_{x+2} \mathrm{O}_{4}(x=0.0,0.1,0.2,0.3)$ samples have been listed in Table 1.

There is a decreasing trend of lattice constant with the variation of $\mathrm{Li}$ content is noticed for the prepared samples. The variation of lattice constant for $\mathrm{Li}_{x-}$ $\mathrm{Ni}_{0.2} \mathrm{Zn}_{0.8-2 . x} \mathrm{Fe}_{x+2} \mathrm{O}_{4}$ is found to be from 8.41 to $8.35 \AA$. The reduction of the lattice constant is might be due to the variation of ionic radius of the samples with the addition of $\mathrm{Li}$ in the compound. A few differences in ionic radius of $\mathrm{Li}$ (0.59 $\AA)$ and other elements [ $\mathrm{Fe}^{3+}(0.645 \AA), \mathrm{Ni}^{2+}(0.69 \AA)$ and $\left.\mathrm{Zn}^{2+}(0.60 \AA)\right]$ [20] is observed. The ionic radius of $\mathrm{Li}^{+}(0.59 \AA)$ is smaller than that of $\mathrm{Zn}^{2+}(0.60 \AA)$ ions which results in a decrease of lattice constant with $\mathrm{Li}$ addition.

Figure 1(b) shows the XRD pattern of $\mathrm{Cu}$ incorporated $\mathrm{Li}_{x} \mathrm{Ni}_{0.2} \mathrm{Zn}_{0.8-2.2} \mathrm{Fe}_{x+2} \mathrm{O}_{4}$ ferrites. The crystal structure of $\mathrm{Li}_{x} \mathrm{Ni}_{0.1} \mathrm{Cu}_{0.1} \mathrm{Zn}_{0.8-2 x} \mathrm{Fe}_{2+x} \mathrm{O}_{4}$ is found to be a cubic spinal structure which implies that addition of $\mathrm{Cu}$ does not affect the crystal structure of $\mathrm{Li}_{x} \mathrm{Ni}_{0.2} \mathrm{Zn}_{0.8-2 x} \mathrm{Fe}_{x+2} \mathrm{O}_{4}$ ferrites. The lattice constant for the $\mathrm{Cu}$ incorporated $\mathrm{Li}-\mathrm{Ni}-\mathrm{Zn}$ ferrites is also reducing with the $\mathrm{Li}$ substitution. Some impurity peaks are noticed in the XRD pattern of $\mathrm{Li}_{x} \mathrm{Ni}_{0.2} \mathrm{Zn}_{0.8-2.2} \mathrm{Fe}_{x+2} \mathrm{O}_{4}(x=0.2)$ ferrites. The unwanted peaks are found to be disappeared when $\mathrm{Cu}$ is incorporated which might be attributed to the good crystallinity of the ferrites because of $\mathrm{Cu}$ 
Table 1. The values of lattice constant, bulk density $\left(\rho_{B}\right)$, porosity $(P)$ and grain size $(D)$ for $\mathrm{Li}_{x} \mathrm{Ni}_{0.2} \mathrm{Zn}_{0.8-2 x} \mathrm{Fe}_{x+2} \mathrm{O}_{4}$ and $\mathrm{Li}_{x-}$ $\mathrm{Ni}_{0.1} \mathrm{Cu}_{0.1} \mathrm{Zn}_{0.8-2 x} \mathrm{Fe}_{2+X} \mathrm{O}_{4},(x=0.0,0.1,0.2,0.3)$ samples sintered at $1150^{\circ} \mathrm{C}$ for 5 hours.

\begin{tabular}{|c|c|c|c|c|c|c|c|c|}
\hline \multirow{2}{*}{$\begin{array}{l}\text { Li content } \\
\quad(x)\end{array}$} & \multicolumn{4}{|c|}{$\mathrm{Ni}_{0.2} \mathrm{Zn}_{0.8-2 x} \mathrm{Li}_{x} \mathrm{Fe}_{2+x} \mathrm{O}_{4}$} & \multicolumn{4}{|c|}{$\mathrm{Li}_{x} \mathrm{Ni}_{0.1} \mathrm{Cu}_{0.1} \mathrm{Zn}_{0.8-2 x} \mathrm{Fe}_{2+x} \mathrm{O}_{4}$} \\
\hline & $a=b=c(\AA)$ & $\rho_{B} \mathrm{gm} / \mathrm{cm}^{-3}$ & $P(\%)$ & $D \mu \mathrm{m}$ & $a=b=c(\AA)$ & $\rho_{B} \mathrm{gm} / \mathrm{cm}^{-3}$ & $P(\%)$ & $D \mu \mathrm{m}$ \\
\hline 0 & 8.41 & 4.00 & 24.99 & 7.192 & 8.42 & 3.8909 & 27.15 & 9.629 \\
\hline 0.1 & 8.40 & 3.73 & 28.25 & 9.665 & 8.31 & 3.7988 & 29.70 & 12.394 \\
\hline 0.2 & 8.37 & 3.89 & 23.82 & 13.188 & 8.39 & 3.9605 & 22.18 & 15.006 \\
\hline 0.3 & 8.35 & 4.06 & 18.50 & 13.192 & 8.36 & 3.8909 & 22.07 & 16.440 \\
\hline
\end{tabular}
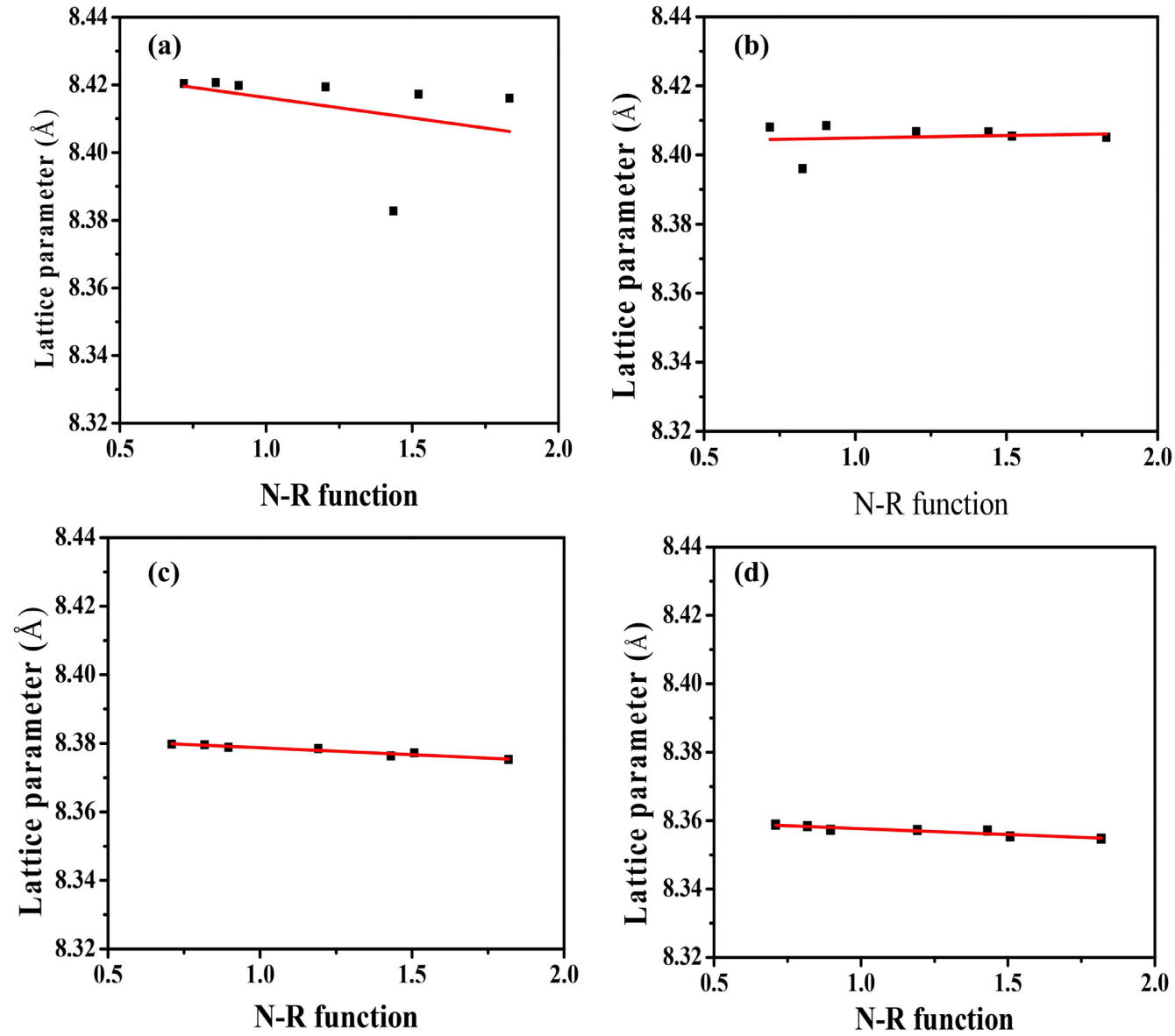

Figure 2. Lattice constant as a function of $F(\theta)$ of $\mathrm{Li}_{x} \mathrm{Ni}_{0.2} \mathrm{Zn}_{0.8-2 x} \mathrm{Fe}_{x+2} \mathrm{O}_{4}$ for (a) $x=0.0$, (b) $x=0.1$, (c) $x$ $=0.2$ and (d) $x=0.3$ ferrites.

addition. The phase formation kinetics of the compound speeded up because of $\mathrm{Cu}$ addition.

\subsection{Density Measurement}

Figure 3(a) illustrates the variation of X-ray density (theoretical density) and bulk density with Li content of $\mathrm{Li}_{x} \mathrm{Ni}_{0.2} \mathrm{Zn}_{0.8-2.2} \mathrm{Fe}_{x+2} \mathrm{O}_{4}$ ferrites. Values of density have an important effect on various properties such as electric as well as magnetic properties of ferrite compounds. Materials having high density contain lower 

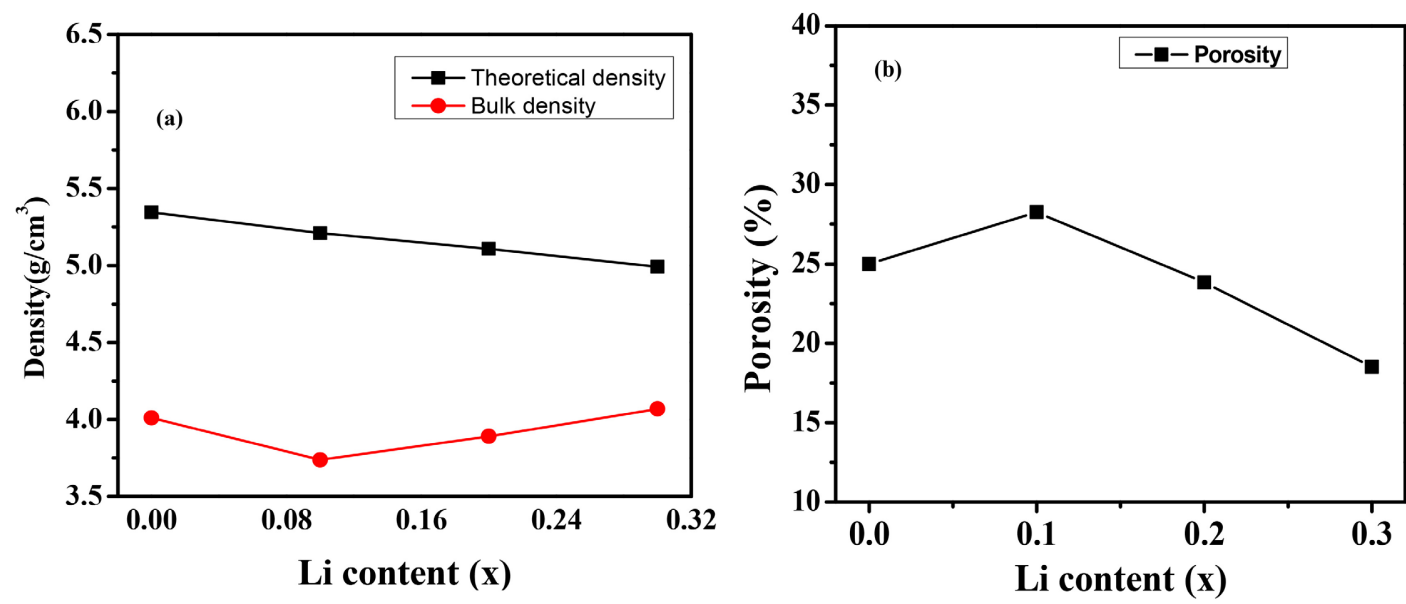

Figure 3. Variation of (a) theoretical density and bulk density and (b) porosity with Li content.

porosity and exhibit good electric and magnetic properties. It is seen in Figure 3(a); the X-ray density decreases with the addition of Li content whereas bulk density is found to be increased. X-ray density is calculated using molecular weight, lattice parameter, etc. Molecular weight of $\mathrm{Li}(6.941 \mathrm{gm} / \mathrm{mol})$ is lower than that of $\mathrm{Zn}(65.4 \mathrm{gm} / \mathrm{mol})$ and thus the $\mathrm{X}$-ray density is reducing gradually with the addition of a low molecular weight element by substituting heavy element.

The variation of porosity with Li content is described in Figure 3(b). It is seen that porosity is reducing with Li content. Voids, pores, etc. remove because of adding $\mathrm{Li}$ and thus the compound becomes denser. The sintering environment may also be an important factor to be denser than the prepared samples. Measured values of X-ray density, bulk density, porosity, etc. are presented in Table 1. It is also noticeable from the graph (Figure 3(a)), the X-ray density is higher than that of bulk density which means when the samples are sintered, they might contain cracks and pores on the microscopic scale and vacancies in the lattice on the atomic scale [21]. The bulk density may have these defects but the X-ray density is precisely measured from the lattice constant, the volume of the unit cell is free from these defects.

Variation of X-ray density and bulk density for $\mathrm{Li}_{x} \mathrm{Ni}_{0.1} \mathrm{Cu}_{0.1} \mathrm{Zn}_{0.8-2 .} \mathrm{Fe}_{2+x} \mathrm{O}_{4},(x$ $=0.0,0.1,0.2,0.3)$ ferrites is illustrated in Figure 4. It shows the same characteristics like the compound $\mathrm{Li}_{x} \mathrm{Ni}_{0.2} \mathrm{Zn}_{0.8-2 x} \mathrm{Fe}_{2+x} \mathrm{O}_{4}$ but the values of bulk density are found to be enhanced because of $\mathrm{Cu}$ incorporation.

\subsection{Microstructural Study}

Figure 5(a) and Figure 5(b) shows the SEM images of $\mathrm{Li}_{x} \mathrm{Ni}_{0.2} \mathrm{Zn}_{0.8-2 . x} \mathrm{Fe}_{2+x} \mathrm{O}_{4}$ and $\mathrm{Li}_{x} \mathrm{Ni}_{0.1} \mathrm{Cu}_{0.1} \mathrm{Zn}_{0.8-2 x} \mathrm{Fe}_{2+x} \mathrm{O}_{4}$ ferrites respectively sintered at $1150^{\circ} \mathrm{C}$ for 5 hours. Microstructure has an influence on the magnetic properties of ferrite materials especially on the measurement of permeability. Microstructures of both ferrites consist of non-uniform, non-repetitive and randomly oriented grains in shape and size. Some intergranular pores are also noticed in the SEM images. The 


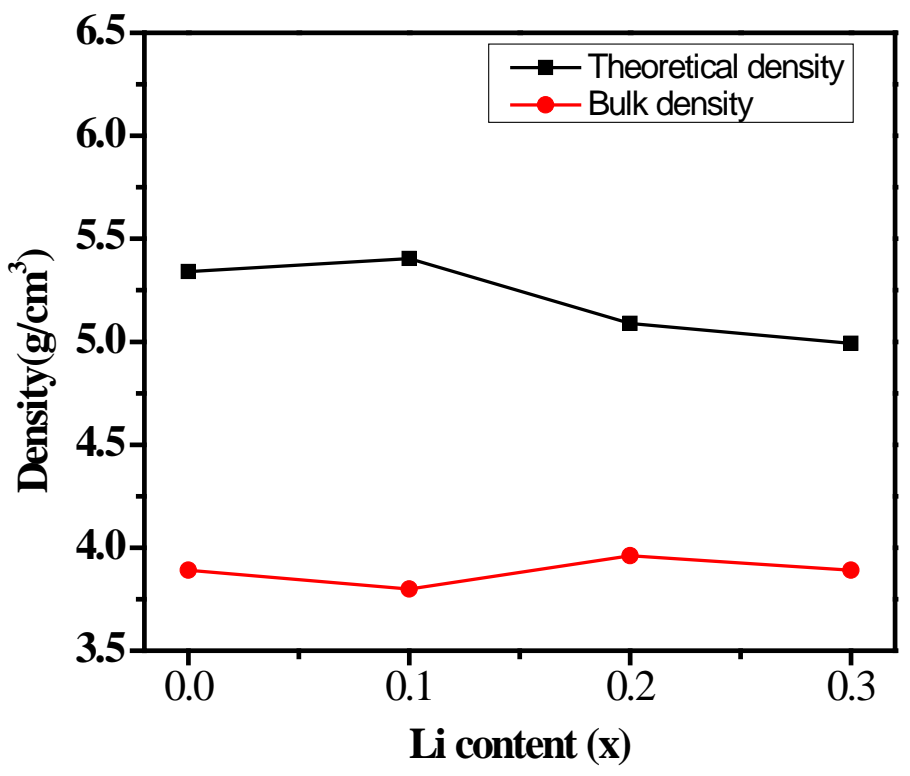

Figure 4. Variation of theoretical density and bulk density of $\mathrm{Li}_{x} \mathrm{Ni}_{0.1} \mathrm{Cu}_{0.1} \mathrm{Zn}_{0.8-2 x} \mathrm{Fe}_{2+x} \mathrm{O}_{4}$, $(x=0.0,0.1,0.2,0.3)$ ferrites with Li content.

(a)
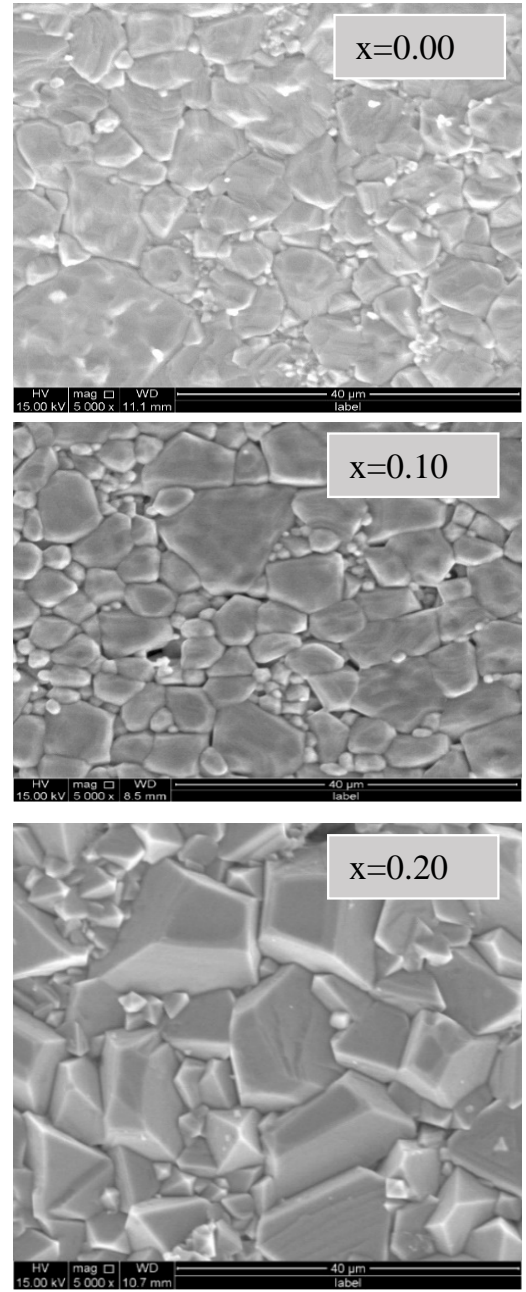

(b)
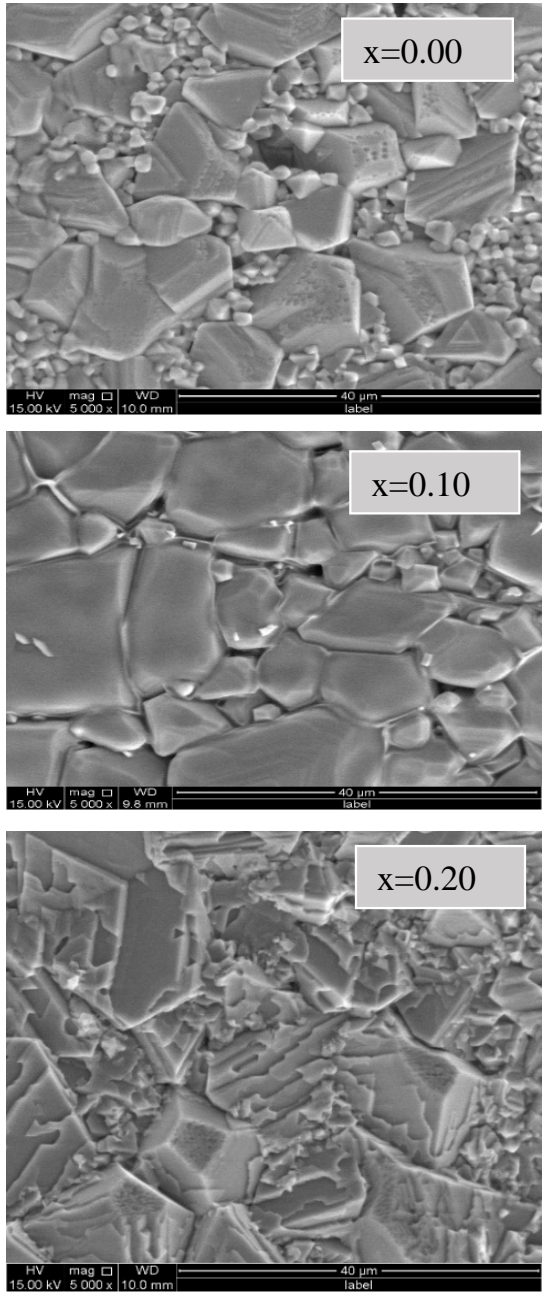

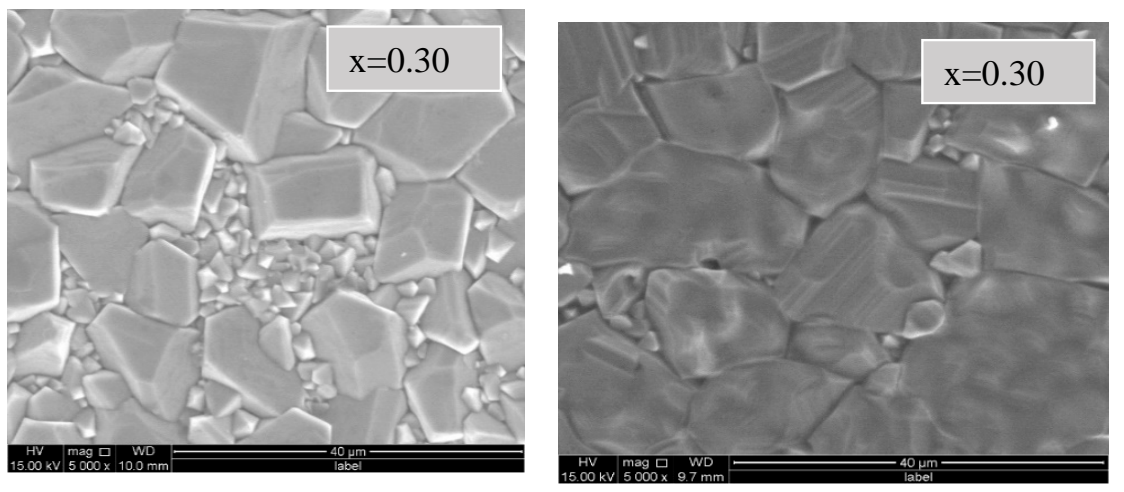

Figure 5. Scanning Electron Microscope (SEM) images of (a) $\mathrm{Li}_{x} \mathrm{Ni}_{0.2} \mathrm{Zn}_{0.8-2 x} \mathrm{Fe}_{2+x} \mathrm{O}_{4}$ and (b) $\mathrm{Li}_{x} \mathrm{Ni}_{0.1} \mathrm{Cu}_{0.1} \mathrm{Zn}_{0.8-2 . x} \mathrm{Fe}_{2+x} \mathrm{O}_{4}$ for $x=0.0$ to 0.3 respectively.

non-uniform grains are obtained may be due to the inhomogeneous driving force of grain boundary movement whereas some uniform grains are existed because of the homogeneous driving force of grain boundary in the grain growth mechanism. The average value of grain size is determined by the linear intercept technique. The magnitude of grain size for both ferrites is presented in Table 1. The average values of grain size are found to be increased with the addition of Li content. The gradual improvement of grain size is attributed might be due to the enhancement of magnetic dipole interaction between the ions because of replacing $\mathrm{Zn}^{2+}$ and $\mathrm{Fe}^{3+}$ ions with $\mathrm{Li}^{+}$.

It is seen in Figure 5(b) and in Table 1, the size of grains for $\mathrm{Li}_{x-}$ $\mathrm{Ni}_{0.1} \mathrm{Cu}_{0.1} \mathrm{Zn}_{0.8-2 x} \mathrm{Fe}_{2+x} \mathrm{O}_{4}$ ferrites is bigger than the grains obtained for $\mathrm{Li}_{x-}$ $\mathrm{Ni}_{0.2} \mathrm{Zn}_{0.8-2 X} \mathrm{Fe}_{2+X} \mathrm{O}_{4}$ which suggest that the addition of $\mathrm{Cu}$ ions modify microstructure. The increase of grain size with the addition of $\mathrm{Cu}$ might be due to the fact that $\mathrm{Cu}$ ions help to complete the sintering process properly and thus increase the molecular concentration at the crystal surface and accelerate the grain growth mechanism.

\subsection{Study of Magnetic Properties}

\subsubsection{Complex Initial Permeability}

Information about the factors that control the magnetic properties of materials and also the adjustability of magnetic materials in high-frequency use can be obtained from complex initial permeability. The complex initial permeability is given by, $\mu_{i}^{*}=\mu_{i}^{\prime}-\mu_{i}^{\prime \prime}$ where $\mu_{i}^{\prime}$ is the real part of complex initial permeability and $\mu_{i}^{\prime \prime}$ is the imaginary part of complex initial permeability. The $\mu_{i}^{\prime}$ represents the energy stored in the system and $\mu_{i}^{\prime \prime}$ describes the dissipation of energy in the system. The variation of the real part of complex initial permeability for the various components of $\mathrm{Li}_{x} \mathrm{Ni}_{0.2} \mathrm{Zn}_{0.8-2 x} \mathrm{Fe}_{2+x} \mathrm{O}_{4}$ ferrites with frequency is shown in Figure 6(a-i).

The values of $\mu_{i}^{\prime}$ for all compositions are found to be almost constant up to a certain frequency. After a certain frequency, they show a slightly rising trend and then fall. The value of $\mu_{i}^{\prime}$ is improved than the parent sample and the best 
(a)
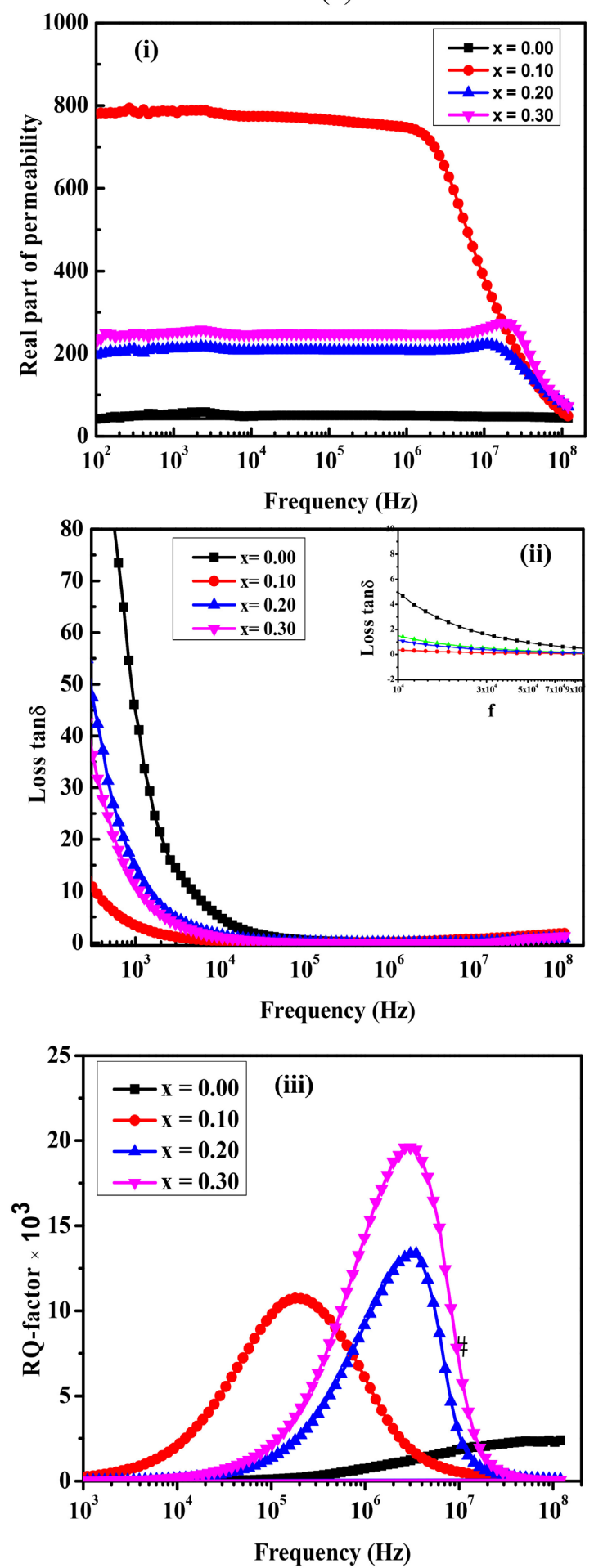

(b)
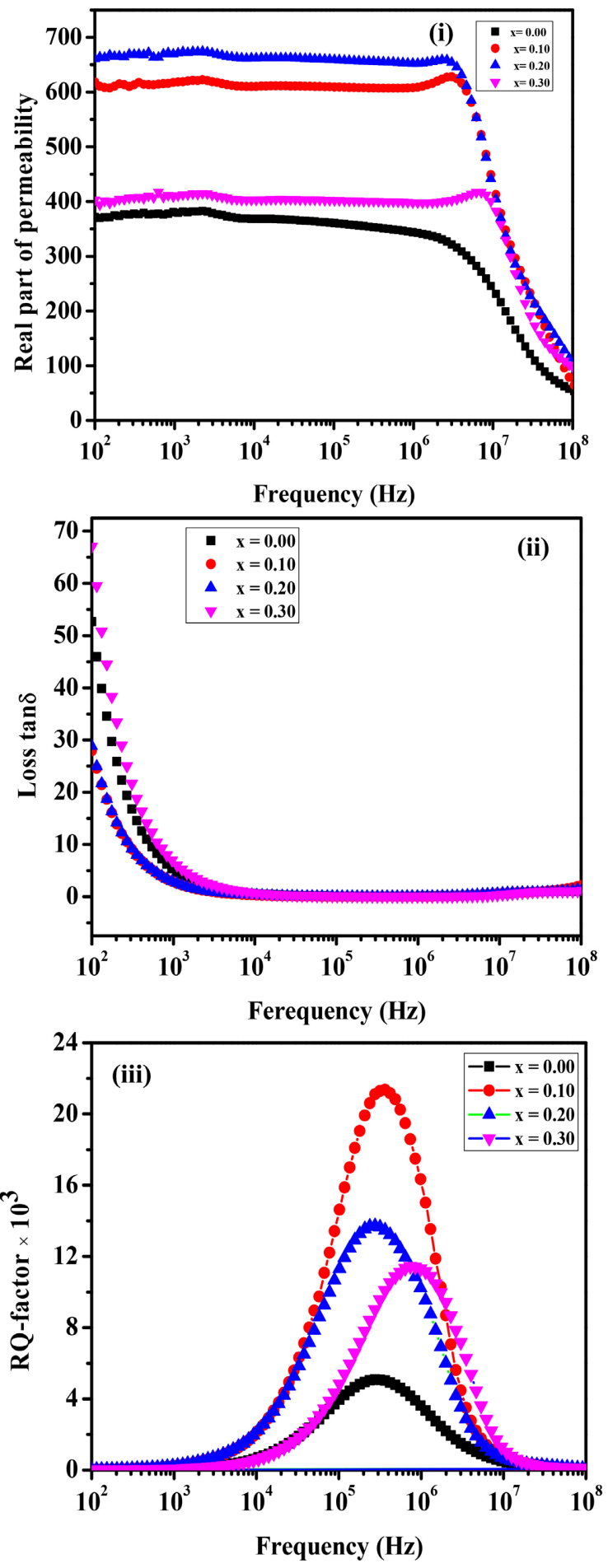

Figure 6. Variation of real part of permeability, loss tangent and relative quality factor of (a) $\mathrm{Li}_{x} \mathrm{Ni}_{0.2} \mathrm{Zn}_{0.8-2.2} \mathrm{Fe}_{2+x} \mathrm{O}_{4}$ and (b) $\mathrm{Li}_{x} \mathrm{Ni}_{0.1} \mathrm{Cu}_{0.1} \mathrm{Zn}_{0.8-2 . x} \mathrm{Fe}_{2+x} \mathrm{O}_{4}$ ferrites with frequency.

result is obtained for $x=0.1$. There are two mechanisms to originate initial permeability in magnetic materials such as spin rotation in the domain and domain wall displacement. Hence, the complex initial permeability is written as [22] 
[23]:

$$
\mu_{i}^{\prime}=1+\chi_{\text {spin }}+\chi_{d w}
$$

where $\chi_{\text {spin }}$ and $\chi_{d w}$ denote the magnetic susceptibility of spin and domain wall motion respectively. $\chi_{\text {spin }}$ and $\chi_{d w}$ can be written as [24]: $\chi_{\text {spin }}=\frac{2 \pi M_{S}^{2}}{K}$ and $\chi_{d w}=\frac{3 \pi M_{S}^{2} D}{4 \gamma}$, where $D$ is the average grain size and $\gamma$ is the domain wall energy.

The influence of spin rotation on initial permeability was found very small than domain wall motion because the motion of the domain wall can continue still in a weak magnetic field [25]. The displacement of the domain wall is varied because of changing sintering temperature and grain size. The motion of the domain wall reduces with the decrease of grain size because the smaller grain contains a lesser number of domain walls and the easy reversal of the domain walls gives initial permeability in the direction of the applied magnetic field. On the other hand, previously published article of Ross [26] and Perduijin et al. [27] reported, when the grain size increases in the ferrite, the permeability increases, and vice versa. However, the $\mathrm{Li}_{x} \mathrm{Ni}_{0.2} \mathrm{Zn}_{0.8-2 x} \mathrm{Fe}_{2+x} \mathrm{O}_{4}$ compound exhibited enhanced complex initial permeability with the addition of Li content which might be attributed to an increase in the size of grains (Figure 5) with Li content. The sample having $10 \% \mathrm{Li}$ content $(x=0.1)$ shows the best result but all the substituted samples have an improved value of $\mu_{i}^{\prime}$ than that of unsubstituted samples which might be due to porosity. The substituted compound has a lower amount of porosity and exhibited better results as pores act as a barrier to the domain wall motion and induce local demagnetizing fields which results in the reduction of $\mu_{i}^{\prime}$ [9] [28].

\subsubsection{Loss Factor $(\tan \delta)$}

The frequency dependence of magnetic loss factor $(\tan \delta)$ at room temperature of $\mathrm{Li}_{x} \mathrm{Ni}_{0.2} \mathrm{Zn}_{0.8-2 x} \mathrm{Fe}_{2+x} \mathrm{O}_{4}$ compound sintered at $1150^{\circ} \mathrm{C}$ for 5 hours is shown in Figure 6(a-ii). The loss tangent $(\tan \delta)$ describes the energy dissipated in the system. All the samples have a high value of loss factor at low frequency. The values of $\tan \delta$ reduce with the increase in frequency and then remain constant. At low frequency, the motion of the domain wall follows the variation of frequency with the change in an external magnetic field but at high frequency, the domain wall becomes unable to follow the variation of the external magnetic field and this might be attributed to exhibiting constant value. It is seen in Figure 6, the Li content samples have a lower value of $\tan \delta$ than unsubstituted ones which indicates that the addition of $\mathrm{Li}$ affects the reduction of loss tangent.

\subsubsection{Relative Quality Factor (RQF)}

Figure 6(a-iii) illustrates the variation of relative quality factor (RQF) with the change in frequency. The RQF determines a range of frequencies where the samples exhibit better performance and it is one of the criteria of the materials to 
be used in microwave devices [29]. RQF has the maximum value at that frequency level where the magnetic loss tangent has the minimum value. The value of RQF first increases slowly with frequency and then rises quite abruptly making a peak at a certain frequency named resonance frequency. All the samples have a broad peak except the unsubstituted sample. The parent sample may have a peak at a high frequency beyond our measurement range.

Figures $6(\mathrm{~b}(\mathrm{i}$-iii) $)$ shows the variation of the real part of permeability, loss tangent, and relative quality factor respectively with the frequency of $\mathrm{Cu}$ included $\mathrm{Li}_{x} \mathrm{Ni}_{0.2} \mathrm{Zn}_{0.8-2 x} \mathrm{Fe}_{2+x} \mathrm{O}_{4}$ ferrites where $\mathrm{Ni}$ was substituted by $\mathrm{Cu}$. A noticeable change is observed in the magnetic properties of $\mathrm{Li}_{x} \mathrm{Ni}_{0.1} \mathrm{Cu}_{0.1} \mathrm{Zn}_{0.8-2 x} \mathrm{Fe}_{2+x} \mathrm{O}_{4}$ ferrites although the magnetic material $\mathrm{Ni}$ was replaced by nonmagnetic $\mathrm{Cu}$. The overall permeability was found to be enhanced and followed Snoek's law [30]. The addition of $\mathrm{Cu}$ in $\mathrm{Li}_{x} \mathrm{Ni}_{0.2} \mathrm{Zn}_{0.8-2 x} \mathrm{Fe}_{2+x} \mathrm{O}_{4}$ ferrites influences density measurement, porosity, and grain size. Moreover, the addition of $\mathrm{Cu}$ helps to complete the sintering process properly. The properties of $\mathrm{Cu}$ mentioned above contribute to improving the permeability, loss tangent, and relative quality factor.

\subsubsection{M-H Hysteresis Loop}

Magnetization vs magnetic field $(\mathrm{M}-\mathrm{H})$ hysteresis loops for each sample of $\mathrm{Li}$ added Ni-Zn $\left(\mathrm{Li}_{x} \mathrm{Ni}_{0.2} \mathrm{Zn}_{0.8-2 . x} \mathrm{Fe}_{2+x} \mathrm{O}_{4}\right)$ ferrites have been described in Figure 7. Like a normal behavior of ferromagnetic materials, magnetization of the prepared ferrite samples is found to increase with applied field and attains a maximum value at higher field except pure Ni-Zn samples. Hysteresis loops of ferrite materials having very low saturation magnetization, approximately zero remanence magnetization indicate paramagnetic behavior at room temperature [31] [32]. The values of saturation magnetization $\left(M_{s}\right)$, remanent magnetization $\left(M_{r}\right)$ and coercivity $\left(H_{c}\right)$ for the prepared samples have been determined from the $\mathrm{M}-\mathrm{H}$ hysteresis loops (Figure 7). The magnetization increased with a sluggish nature until it gets the maximum value due to the spin rotation up to $x=0.2$. This variation of room temperature saturation magnetization with the increase in $\mathrm{Li}$ and $\mathrm{Fe}$ content is related to 1) the modification of predominant exchange interactions between the cations; 2) substitution of paramagnetic ( $\mathrm{Li}$ ) and ferromagnetic $(\mathrm{Fe})$ ions for the diamagnetic $\left.\mathrm{Zn}^{2+} ; 3\right)$ cation redistribution in the spinel lattice due to addition of $\mathrm{Li}$ and $\mathrm{Fe}$ ions [33].

The mechanism has also been explained in terms of spin-disorder, spin canting, and spin-glass-like state in the surface layers of the nanoparticles due to the local chemical disorder, broken exchange interaction and a dissimilar local symmetry for those atoms near the surface. As the divalent $\mathrm{Cu}^{2+}$ and $\mathrm{Zn}^{2+} \mathrm{ca}-$ tions have a tendency to occupy both sites (octahedral and tetrahedral sites), so they can form the mixed spinel structure. Mixed spinel configurations are characterized by the degree of inversion, which depends strongly on the preparation procedures [34]. The increase in saturation magnetization with increasing Li and Fe concentration from $x=0$ to 0.20 suggests Neel's two-sub-lattice model which stated that the resultant magnetization of the samples varies with the difference 

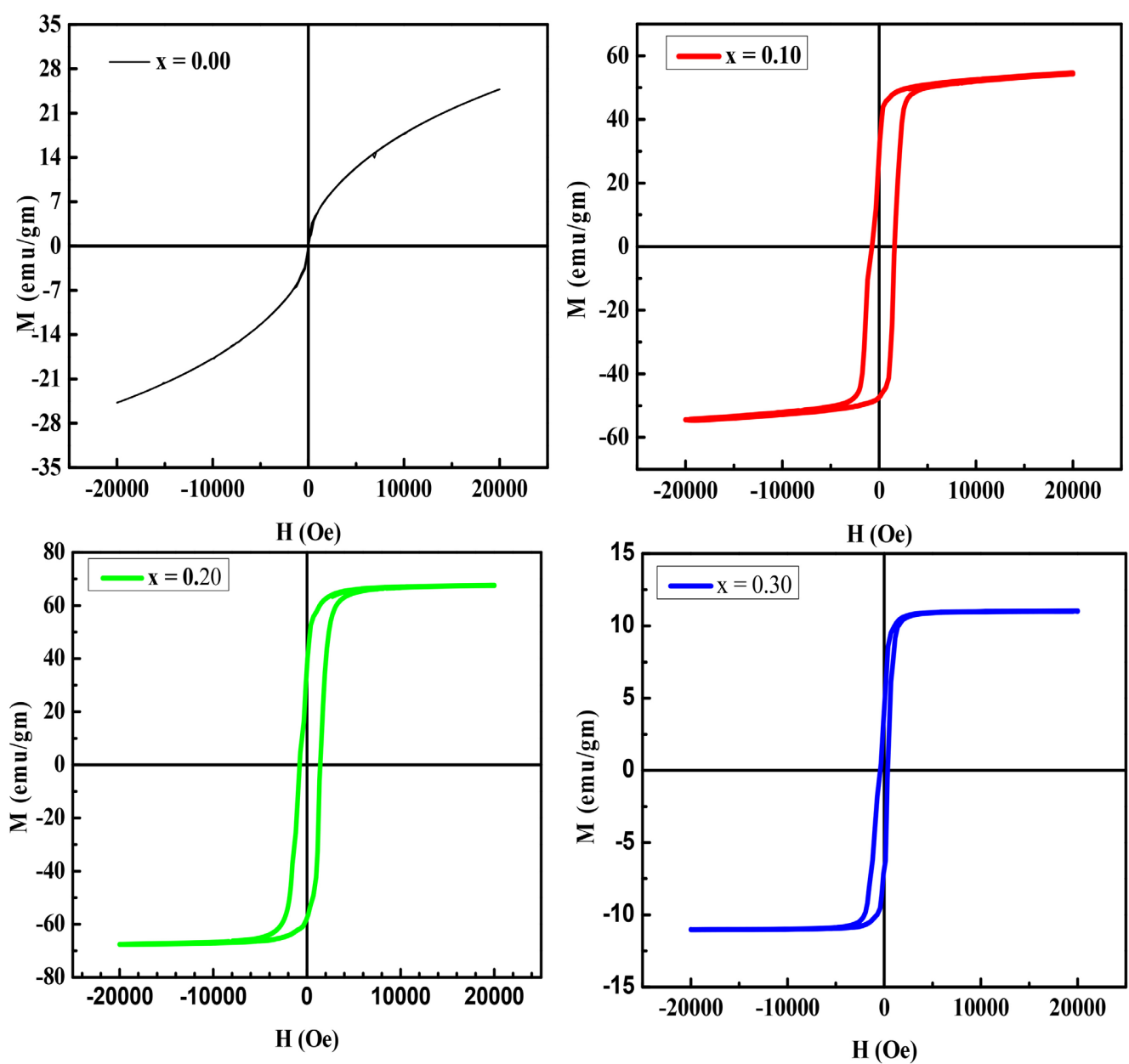

Figure 7. $\mathrm{M}-\mathrm{H}$ loop of $\mathrm{Li}_{x} \mathrm{Ni}_{0.2} \mathrm{Zn}_{0.8-2 x} \mathrm{Fe}_{x+2} \mathrm{O}_{4}$ spinel ferrites at room temperature.

of the B-site and A-site magnetization $\left(M=M_{\mathrm{B}}-M_{\mathrm{A}}\right)$ [35] [36]. The possible cation distribution for $\mathrm{Ni}_{0.2} \mathrm{Zn}_{0.8-2 x} \mathrm{Li}_{x} \mathrm{Fe}_{2+x} \mathrm{O}_{4}$ ferrites for $0 \leq x \leq 0.20$ can be expressed as the following:

$$
\left(\mathrm{Zn}_{0.8-2 x}^{2+} \mathrm{Li}_{x}^{+} \mathrm{Fe}_{0.85}^{3+}\right)_{\mathrm{A}}\left[\mathrm{Ni}_{0.2}^{2+} \mathrm{Fe}_{1.15+x}^{3+}\right]_{\mathrm{B}} \mathrm{O}_{4}
$$

Here, the bracket () and [] specify the tetrahedral A-site and octahedral B-site, respectively. The cation distribution is attained from a few particulars [37]. They are as follows: 1) Diamagnetic $\mathrm{Zn}^{2+}$ ion prefers to occupy both the tetrahedral A-site and octahedral B-sites [38] [39]; 2) $\mathrm{Ni}^{2+}$ prefers to go to the octahedral B-site [40]; 3) it is evident that the $\mathrm{Li}^{+}$ion has tetrahedral site preference in spinel structure and $\mathrm{Cu}^{2+}$ has octahedral site preference [41].

According to the above cation distribution of the prepared samples and using the values of the magnetic moments of $\mathrm{Zn}^{2+}\left(0 \mu_{B}\right), \mathrm{Ni}^{2+}\left(2 \mu_{B}\right), \mathrm{Li}^{+}\left(0 \mu_{B}\right)$, and $\mathrm{Fe}^{3+}\left(5 \mu_{B}\right)$ [41] [42], the total magnetization for $x=0.00$ to 0.20 is expected to be high, where $\mu_{B}$ is the Bohor magneton number $\left(9.27 \times 10^{-24}\right.$ joule per tesla). Due to the high amount of diamagnetic $\mathrm{Zn}$ content on the tetrahedral sites $(\geq 0.4)$, a deficiency of $\mathrm{Fe}^{3+}$ ions on the tetrahedral sites creates and the moments of both sites are not ordered anymore. Then the B lattice divides itself into sub-lattices; 
the magnetization of the B sub-lattices makes $\mathrm{Y}-\mathrm{K}$ angle with each other differing from 0 or $180^{\circ}$ regarding the strength of B-B to A-B interactions [43] [44]. In that case, the total magnetization can be rewritten as (Table 2),

$$
M=(5 x+1.9 \theta Y K) \mu_{B}
$$

So, the cation distribution and the exchange interactions between A-sites and B-sites may justify the observed variation in $M_{S}$. For the $x=0.30$ sample the saturation magnetization is decreased due to the possible influx of the paramagnetic $\mathrm{Zn}^{2+}$ ions to the octahedral sites in replace of ferromagnetic $\mathrm{Fe}^{3+}$ ions to the tetrahedral sites. This result not only decreases the magnetic moment difference between the A \& B-sites but also modifies largely the prevailing exchange interactions. The rearrangement of cations distribution and magnetization for $x=$ 0.30 sample are,

$$
\left(\mathrm{Li}_{x}^{+} \mathrm{Fe}_{0.80+x}^{3+}\right)_{\mathrm{A}}\left[\mathrm{Zn}_{0.8-2 x}^{2+} \mathrm{Ni}_{0.2}^{2+} \mathrm{Fe}_{1.20}^{3+}\right]_{\mathrm{B}} \mathrm{O}_{4} \text { and } M=(2.4-5 x) \mu_{B}
$$

Figure 8 depicts the room temperature $\mathrm{M}-\mathrm{H}$ loops of $\mathrm{Ni}-\mathrm{Li}-\mathrm{Cu}-\mathrm{Zn}$ ferrites that have been sintered at $1150^{\circ} \mathrm{C}$ for $5 \mathrm{~h}$. Paramagnetic divalent $\mathrm{Cu}$ ions can occupy both sites of the spinel ferrite [33] [41]. It is observed that when $10 \%$ ferromagnetic $\mathrm{Ni}$ ions are replaced by $10 \%$ paramagnetic $\mathrm{Cu}$ ions, the net magnetic moments of (difference between B-sites and A-sites) the spinel ferrites have been decreased. Since Li-ions occupied in the tetrahedral sites and Fe ions occupied in both sites the possible cations distribution can be written as,

$$
\left(\mathrm{Zn}_{0.8-2 x}^{2+} \mathrm{Li}_{x}^{+} \mathrm{Fe}_{0.85}^{3+}\right)_{\mathrm{A}}\left[\mathrm{Ni}_{0.1}^{2+} \mathrm{Cu}_{0.1}^{2+} \mathrm{Fe}_{1.15+x}^{3+}\right]_{\mathrm{B}} \mathrm{O}_{4}
$$

From Figure 8, it is also noticeable that saturation magnetization is gradually increased with $\mathrm{Li}$ and $\mathrm{Fe}$ content. The cation distribution reflects this increment because ferromagnetic $\mathrm{Ni}^{2+}\left(2 \mu_{B}\right)$ and paramagnetic $\mathrm{Cu}^{2+}\left(1 \mu_{B}\right)$ ions occupied in the $\mathrm{B}$ sites and the diamagnetic $\mathrm{Zn}$ and paramagnetic Li occupied in the A-sites; therefore, net magnetic moments have been increased gradually. Expected increased magnetization can be written as,

$$
M=(1.8+5 x) \mu_{B}
$$

where $\mu_{B}$ is the Bohor magneton number. The experimental number of Bohr

\begin{tabular}{|c|c|c|c|c|c|c|c|c|}
\hline \multirow{2}{*}{$x$} & \multicolumn{4}{|c|}{$\mathrm{Li}_{x} \mathrm{Ni}_{0.2} \mathrm{Zn}_{0.8-2 x} \mathrm{Fe}_{2+x} \mathrm{O}_{4}$} & \multicolumn{4}{|c|}{$\mathrm{Li}_{x} \mathrm{Ni}_{0.1} \mathrm{Cu}_{0.1} \mathrm{Zn}_{0.8-2 x} \mathrm{Fe}_{2+x} \mathrm{O}_{4}$} \\
\hline & $M(\mathrm{amu})$ & $M_{s}(\mathrm{emu} / \mathrm{gm})$ & $\mu_{\exp }\left(\mu_{B}\right)$ & $\mu_{t h}\left(\mu_{B}\right)$ & $\mathbf{M}(\mathrm{amu})$ & $M_{s}(\mathrm{emu} / \mathrm{gm})$ & $\mu_{\exp }\left(\mu_{B}\right)$ & $\mu_{t h}\left(\mu_{B}\right)$ \\
\hline 0.00 & 239.759 & 25 & 1.07 & 1.9 & 240.244 & 24.5 & 1.05 & 1.8 \\
\hline 0.10 & 227.479 & 54 & 2.20 & 2.4 & 233.449 & 46.00 & 1.92 & 2.3 \\
\hline 0.20 & 215.199 & 68 & 2.62 & 2.9 & 226.65 & 48.00 & 1.95 & 2.8 \\
\hline 0.30 & 202.919 & 11 & 0.40 & 0.9 & 219.859 & 60.00 & 2.38 & 3.3 \\
\hline
\end{tabular}
magnetons has been determined from the formula $\frac{M_{s} M}{5585}$ [45], where $M_{s}$ is the

Table 2. Molecular weight $(M)$, saturation magnetization $\left(M_{s}\right)$, experimental $\left(\mu_{\text {exp }}\right)$ and theoretical $\left(\mu_{t h}\right)$ Bohr magneton number for $\mathrm{Li}_{X} \mathrm{Ni}_{0.2} \mathrm{Zn}_{0.8-2 X} \mathrm{Fe}_{2+X} \mathrm{O}_{4}$ and $\mathrm{Li}_{X} \mathrm{Ni}_{0.1} \mathrm{Cu}_{0.1} \mathrm{Zn}_{0.8-2 X} \mathrm{Fe}_{2+X} \mathrm{O}_{4}$ spinel ferrite. 

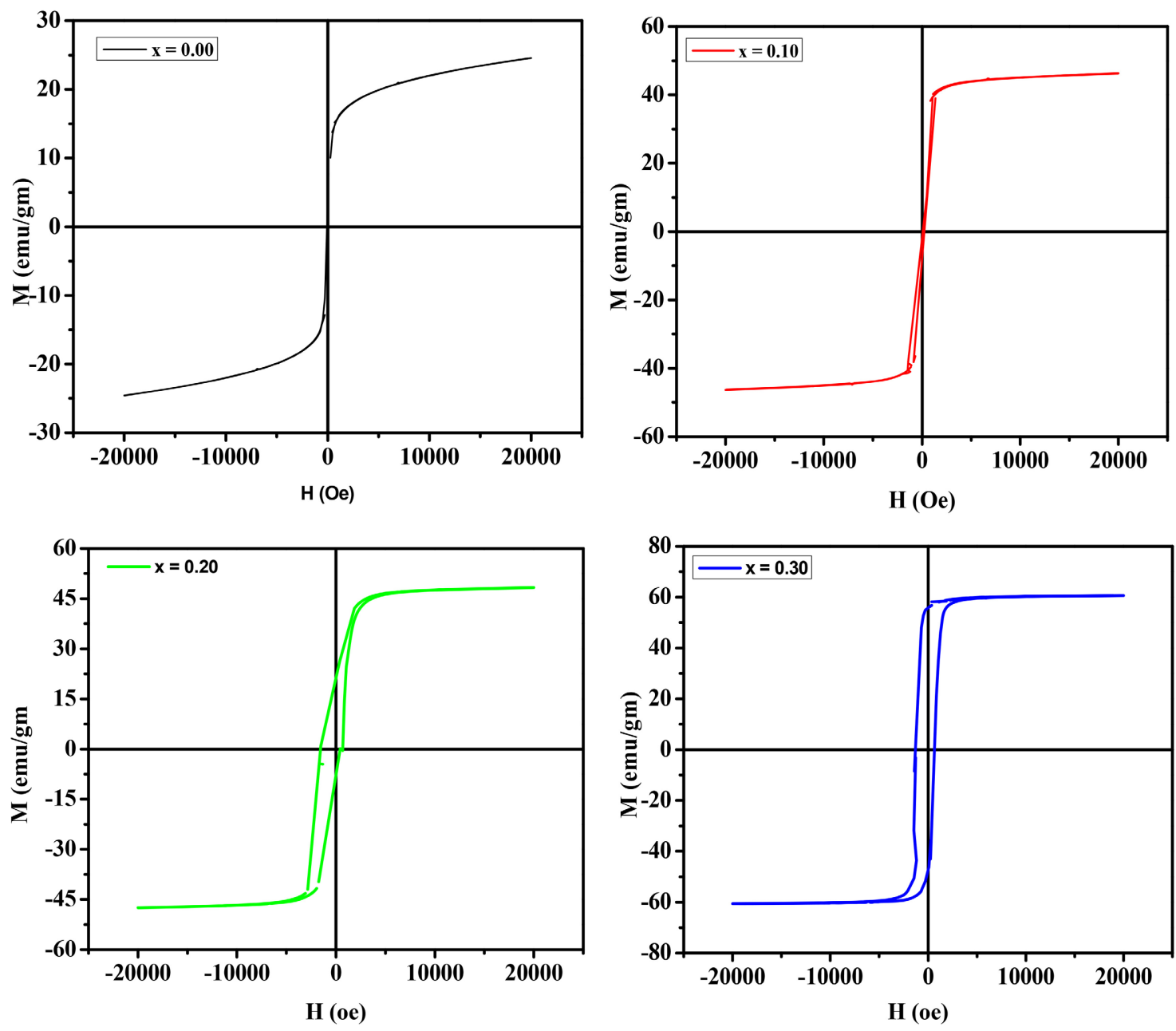

Figure 8. Room temperature $\mathrm{M}-\mathrm{H}$ loop of $\mathrm{Li}_{x} \mathrm{Ni}_{0.1} \mathrm{Cu}_{0.1} \mathrm{Zn}_{0.8-2 x} \mathrm{Fe}_{2+x} \mathrm{O}_{4}$ ferrites for $x=0.00$ to 0.30 respectively sintered at $1150^{\circ} \mathrm{C}$ temperature.

experimental saturation magnetization, $M$ is the molecular weight of the Ni-Li-Zn, and Ni-Li-Cu Zn ferrite samples. The theoretical number of Bohr magnetons $\left(\mu_{t h}\right)$ is obtained from the cation distribution and is strictly valid at 0 $\mathrm{K}$ by considering the spin moments on the $\mathrm{A}$ and B-sublattices aligned exactly antiparallel and are slightly higher compared to the experimental value. This variation can be explained based on the fact that the experimental value has been determined from the saturation magnetization measured at room temperature in which the magnetic spins on the A and B-sites may not be truly antiparallel as an effect of temperature. The variation of remanent magnetization and coercivity can be explained based on the magnetocrystalline anisotropy, particle morphology, dimension of the crystals, residual stress, and crystal imperfections [46].

\section{Conclusion}

Various compositions of non-magnetic $\mathrm{Cu}$ ion added and $\mathrm{Li}$ doped $\mathrm{Ni}-\mathrm{Zn}$ ferrites were synthesized by the conventional solid-state reaction technique. The effect of $\mathrm{Cu}$, as well as $\mathrm{Li}$ on different properties of the prepared samples such as 
crystal structure, density and porosity, microstructure, complex initial permeability, loss factor and magnetization, were studied. Polycrystalline $\mathrm{Li}_{x-}$ $\mathrm{Ni}_{0.2} \mathrm{Zn}_{0.8-2 x} \mathrm{Fe}_{x+2} \mathrm{O}_{4}$ and $\mathrm{Li}_{x} \mathrm{Ni}_{0.1} \mathrm{Cu}_{0.1} \mathrm{Zn}_{0.8-2 x} \mathrm{Fe}_{x+2} \mathrm{O}_{4}(x=0.0,0.1,0.2$ and 0.3$)$ ferrites had spinal cubic structure. All the compositions exhibited good crystallinity. There was no effect of $\mathrm{Cu}$ addition on the crystal structure. The studied samples had high density. The values of density increased with the addition of Li content whereas porosity reduced gradually. The $\mathrm{Cu}$ included samples showed better results. Microstructure of $\mathrm{Li}_{x} \mathrm{Ni}_{0.2} \mathrm{Zn}_{0.8-2 x} \mathrm{Fe}_{x+2} \mathrm{O}_{4}$ and $\mathrm{Li}_{x} \mathrm{Ni}_{0.1} \mathrm{Cu}_{0.1} \mathrm{Zn}_{0.8-2 x} \mathrm{Fe}_{x+2} \mathrm{O}_{4}$ was measured using Scanning Electron Microscope (SEM) and average grain size was determined from the collected images following linear intercept technique. The values of grain size were found to be enhanced with the addition of Li. Nonuniform and nonrepetitive grains were seen. $\mathrm{Li}_{x} \mathrm{Ni}_{0.1} \mathrm{Cu}_{0.1} \mathrm{Zn}_{0.8-2 x} \mathrm{Fe}_{x+2} \mathrm{O}_{4}$ compound had bigger size grains. The overall complex initial permeability properties such as real part of complex initial permeability, loss tangent and quality factor were improved. The real part of complex initial permeability increased whereas loss tangent reduced with the rising of $\mathrm{Li}$ content. The compound containing $\mathrm{Cu}$ showed better results because of the bigger size grains of these compositions. The $\mathrm{M}-\mathrm{H}$ hysteresis loops were determined using Vibrating Sample Magnetometer (VSM) and the values of magnetization were measured for both $\mathrm{Li}_{x-}$ $\mathrm{Ni}_{0.2} \mathrm{Zn}_{0.8-2 x} \mathrm{Fe}_{x+2} \mathrm{O}_{4}$ and $\mathrm{Li}_{x} \mathrm{Ni}_{0.1} \mathrm{Cu}_{0.1} \mathrm{Zn}_{0.8-2 x} \mathrm{Fe}_{x+2} \mathrm{O}_{4}$ ferrites. Saturation magnetization was increased with the rising of Li content and the $\mathrm{Cu}$ added samples exhibited higher values and this might be attributed to change in cation distribution.

\section{Conflicts of Interest}

The authors declare no conflicts of interest regarding the publication of this paper.

\section{References}

[1] Bragg, W.H. (1915) XXX. The Structure of the Spinel Group of Crystals. The London, Edinburgh and Dublin Philosophical Magazine and Journal of Science, 30, 305-315. https://doi.org/10.1080/14786440808635400

[2] Feng, Y., Chen, Y., Ren, Y., Zhang, H. and Cao, S. (2020) Synthesis and Crystal Structure Studies of Mitomycin C Dihydrate. Crystal Structure Theory and Applications, 9, 13-21. https://doi.org/10.4236/csta.2020.92002

[3] Moriguchi, T., Okuyama, M. and Jalli, V. (2021) Design, Synthesis, Crystal Structure and Photophysical Properties of New Oxadiazole Extended Viologen Fluorophore. Crystal Structure Theory and Applications, 10, 27-37. https://doi.org/10.4236/csta.2021.102003

[4] Hossain, A.K.M.A., Mahmud, S.T., Seki, M., Kawai, T. and Tabata, H. (2007) Structural, Electrical Transport, and Magnetic Properties of $\mathrm{Ni}_{1-\mathrm{x}} \mathrm{Zn}_{\mathrm{x}} \mathrm{Fe}_{2} \mathrm{O}_{4}$. Journal of Magnetism and Magnetic Materials, 312, 210-219. https://doi.org/10.1016/j.jmmm.2006.09.030

[5] Verma, A., Goel, T.C., Mendiratta, R.G. and Alam, M.I. (1999) Dielectric Properties of NiZn Ferrites Prepared by the Citrate Precursor Method. Materials Science and Engineering: B, 60, 156-162. https://doi.org/10.1016/S0921-5107(99)00019-7 
[6] Modak, S., Ammar, M., Mazaleyrat, F., Das, S. and Chakrabarti, P.K. (2009) XRD, HRTEM and Magnetic Properties of Mixed Spinel Ni-Zn-Cu-Ferrite. Journal of alloys and compounds, 473, 15-19. https://doi.org/10.1016/j.jallcom.2008.06.020

[7] Hsu, W.-C., Chen, S.C., Kuo, P.C., Lie, C.T. and Tsai, W.S. (2004) Preparation of NiCuZn Ferrite Nanoparticles from Chemical Co-Precipitation Method and the Magnetic Properties after Sintering. Materials Science and Engineering: B, 111, 142-149. https://doi.org/10.1016/j.mseb.2004.04.009

[8] Rahman, I.Z. and Ahmed, T.T. (2005) A Study on Cu Substituted Chemically Processed Ni-Zn-Cu Ferrites. Journal of Magnetism and Magnetic Materials, 290-291, 1576-1579. https://doi.org/10.1016/j.jmmm.2004.11.250

[9] Shrotri, J.J., Kulkarni, S.D., Deshpande, C.E., Mitra, A., Sainkar, S.R., Anil Kumar, P.S. and Date, S.K. (1999) Effect of Cu Substitution on the Magnetic and Electrical Properties of Ni-Zn Ferrite Synthesised by Soft Chemical Method. Materials Chemistry and Physics, 59, 1-5. https://doi.org/10.1016/j.mseb.2004.04.009

[10] Dimri, M.C., Verma, A., Kashyap, S.C., Dube, D.C., Thakur, O.P. and Prakash, C. (2006) Structural, Dielectric and Magnetic Properties of NiCuZn Ferrite Grown by Citrate Precursor Method. Materials Science and Engineering: B, 133, 42-48. https://doi.org/10.1016/j.mseb.2006.04.043

[11] Mürbe, J. and Töpfer, J. (2006) Ni-Cu-Zn Ferrites for Low Temperature Firing: II. Effects of Powder Morphology and $\mathrm{Bi}_{2} \mathrm{O}_{3}$ Addition on Microstructure and Permeability. Journal of Electroceramics, 16, 199-205. https://doi.org/10.1007/s10832-006-6362-9

[12] Qiu, J., Lan, L., Zhang, H. and Gu, M. (2008) Effect of Titanium Dioxide on Microwave Absorption Properties of Barium Ferrite. Journal of Alloys and Compounds, 453, 261-264. https://doi.org/10.1016/j.jallcom.2006.11.059

[13] Hankare, P.P., Patil, R.P., Sankpal, U.B., Jadhav, S.D., Mulla, I.S., Jadhav, K.M. and Chougule, B.K. (2009) Magnetic and Dielectric Properties of Nanophase Manganese-Substituted Lithium Ferrite. Journal of Magnetism and Magnetic Materials, 321, 3270-3273. https://doi.org/10.1016/j.jmmm.2009.05.074

[14] Ott, G., Wrba, J. and Lucke, R. (2003) Recent Developments of Mn-Zn Ferrites for High Permeability Applications. Journal of Magnetism and Magnetic Materials, 254-255, 535-537. https://doi.org/10.1016/S0304-8853(02)00961-7

[15] Ghazanfar, U., Siddiqi, S.A. and Abbas, G. (2005) Structural Analysis of the Mn-Zn Ferrites Using XRD Technique. Materials Science and Engineering. B, 118, 84-86. https://doi.org/10.1016/j.mseb.2004.12.018

[16] Sugimoto, S., Haga, K., Kagotani, T. and Inomata, K. (2005) Microwave Absorption Properties of Ba M-Type Ferrite Prepared by a Modified Coprecipitation Method. Journal of Magnetism and Magnetic Materials, 290-291, 1188-1191. https://doi.org/10.1016/j.jmmm.2004.11.381

[17] Nakamura, T., Miyamoto, T. and Yamada, Y. (2003) Complex Permeability Spectra of Polycrystalline Li-Zn Ferrite and Application to EM-Wave Absorber. Journal of Magnetism and Magnetic Materials, 256, 340-347.

https://doi.org/10.1016/S0304-8853(02)00698-4

[18] Li, L.-Z., Peng, L., Zhong, X.-X., Wang, R. and Tu, X.-Q. (2016) Structural and Magnetic Properties of Strontium Substituted NiZn Ferrite Nanopowders. Ceramics International, 42, 13238-13241. https://doi.org/10.1016/j.ceramint.2016.05.120

[19] Loganathan, A. and Kumar, K. (2016) Effects on Structural, Optical, and Magnetic Properties of Pure and Sr-Substituted $\mathrm{MgFe}_{2} \mathrm{O}_{4}$ Nanoparticles at Different Calcination Temperatures. Applied Nanoscience, 6, 629-639. 
https://doi.org/10.1007/s13204-015-0480-0

[20] Peng, Z., Fu, X., Ge, H., Fu, Z., Wang, C., Qi, L. and Miao, H. (2011) Effect of Pr3+ doping on Magnetic and Dielectric Properties of Ni-Zn Ferrites by "One-Step Synthesis". Journal of Magnetism and Magnetic Materials, 323, 2513-2518. https://doi.org/10.1016/j.jmmm.2011.05.033

[21] Nabiyouni, G., Jafari Fesharaki, M., Mozafari, M. and Amighian, J. (2010) Characterization and Magnetic Properties of Nickel Ferrite Nanoparticles Prepared by Ball Milling Technique. Chinese Physics Letters, 27, Article ID: 126401. https://doi.org/10.1088/0256-307X/27/12/126401

[22] Ahmed, M.A., Okasha, N. and Salah, L. (2003) Influence of Yttrium Ions on the Magnetic Properties of Ni-Zn Ferrites. Journal of Magnetism and Magnetic Materials, 264, 241-250. https://doi.org/10.1016/S0304-8853(03)00212-9

[23] Verma, A., Goel, T.C., Mendiratta, R.G. and Kishan, P. (2000) Magnetic Properties of Nickel-Zinc Ferrites Prepared by the Citrate Precursor Method. Journal of Magnetism and Magnetic Materials, 208, 13-19. https://doi.org/10.1016/S0304-8853(99)00585-5

[24] Globus, A. and Duplex, P. (1966) Separation of Susceptibility Mechanisms for Ferrites of Low Anisotropy. IEEE Transactions on Magnetics, 2, 441-445. https://doi.org/10.1109/TMAG.1966.1065867

[25] Snelling, E.C. (1969) Soft Ferrites: Properties and Applications. First Edition, I life Books Ltd., London.

[26] Rosses, E., Hanke, I. and Moser, E. (1964) Zeitschrift für angewandte Mathematik und Physik, 17, 504.

[27] Perduijin, D.J., Pel Oscheek, H.P. (1968) Proceedings of the British Ceramic Society, $10,263$.

[28] Gupta, N., Dimri, M.C., Kashyap, S.C. and Dube, D.C. (2005) Processing and Properties of Cobalt-Substituted Lithium Ferrite in the GHz Frequency Range. Ceramics International, 31, 171-176. https://doi.org/10.1016/j.ceramint.2004.04.004

[29] Brockman, F.G., Dowling, P.H. and Steneck, W.G. (1950) Dimensional Effects Resulting from a High Dielectric Constant Found in a Ferromagnetic Ferrite. Physical Review, 77, 85-93. https://doi.org/10.1103/PhysRev.77.85

[30] Snoek, J.L. (1948) Dispersion and Absorption in Magnetic Ferrites at Frequencies Above One Mc/s. Physica, 14, 207-217. https://doi.org/10.1016/0031-8914(48)90038-X

[31] Kurmude, D.V., Kale, C.M., Aghav, P.S., Shengule, D.R. and Jadhav, K.M. (2014) Superparamagnetic Behavior of Zinc-Substituted Nickel Ferrite Nanoparticles and Its Effect on Mossbauer and Magnetic Parameters. Journal of Superconductivity and Novel Magnetism, 27, 1889-1897. https://doi.org/10.1007/s10948-014-2535-y

[32] Slama, J., Usak, E.Í., Martin, S., Gruskova, A., Usakova, M. and Jancárik, V. (2010) Analysis of Selected Be-Substituted NiZn Ferrites. IEEE Transactions on Magnetics, 46, 447-450. https://doi.org/10.1109/TMAG.2009.2033556

[33] Siva Ram Prasad, M. and Vara Prasad, B.B.V.S. (2018) Influence of Divalent Copper Substitution on the Properties of Nanocrystalline Ni-Zn Ferrites Prepared by the Citrate-Gel Autocombustion Method. International Journal of Advance Research in Science and Engineering, 7, 228-240.

[34] Rashad, M.M., Elsayed, E.M., Moharam, M.M., Abou-Shahba, R.M. and Saba, A.E. (2009) Structure and Magnetic Properties of $\mathrm{Ni}_{\mathrm{x}} \mathrm{Zn}_{1-\mathrm{x}} \mathrm{Fe}_{2} \mathrm{O}_{4}$ Nanoparticles Prepared through Co-Precipitation Method. Journal of Alloys and Compounds, 486, 759-767. 
https://doi.org/10.1016/j.jallcom.2009.07.051

[35] Yafet, Y. and Kittel, C. (1952) Antiferromagnetic Arrangements in Ferrites. Physical Review, 87, 290-294. https://doi.org/10.1103/PhysRev.87.290

[36] Iwauchi, K. (1971) Dielectric Properties of Fine Particles of $\mathrm{Fe}_{3} \mathrm{O}_{4}$ and Some Ferrites. Japanese Journal of Applied Physics, 10, 1520-1528. https://doi.org/10.1143/JJAP.10.1520

[37] Petit, F. and Lenglet, M. (1993) Spectroscopic Evidence of the $\mathrm{Mn}^{3+}-\mathrm{Fe}^{2+}$ Octahedral Pair in Lithium-Manganese Ferrites Near the Order-Disorder Transition. Solid state communications, 86, 67-71. https://doi.org/10.1016/0038-1098(93)90923-B

[38] Haque, M.M., Maria, K.H., Choudhury, S., Bhuiyan, M.A. and Hakim, M.A. (2013) Synthesis, Microstructure and Magnetic Properties of Ni-Mg Ferrites. Journal of Ceramic Processing Research, 14, 82-86.

[39] Ding, L.L., Xue, L.C., Li, Z.Z., Li, S.Q., Tang, G.D., Qi, W.H., Wu, L.Q. and Ge, X.S.. (2016) Study of Cation Distributions in Spinel Ferrites $\mathrm{M}_{\mathrm{x}} \mathrm{Mn}_{1-\mathrm{x}} \mathrm{Fe}_{2} \mathrm{O}_{4}(\mathrm{M}=\mathrm{Zn}, \mathrm{Mg}$, Al). AIP Advances, 6, Article ID: 105012. https://doi.org/10.1063/1.4966253

[40] Nath, S.K., Maria, K.H., Noor, S., Sikder, S.S., Manjura Hoque, S. and Hakim, M.A. (2012) Magnetic Ordering in Ni-Cd Ferrite. Journal of Magnetism and Magnetic Materials, 324, 2116-2120. https://doi.org/10.1016/j.jmmm.2012.02.023

[41] Rasheed, S., Sartaj Aziz, H., Khan, R.A., Khan, A.M., Rahim, A., Nisar, J., Mujtaba Shah, S., Iqbal, F. and Khan, A.R. (2016) Effect of Li-Cu Doping on Structural, Electrical and Magnetic Properties of Cobalt Ferrite Nanoparticles. Ceramics International, 42, 3666-3672. https://doi.org/10.1016/j.ceramint.2015.11.034

[42] KaziHanium, M., Akther, U.S., Esha, I.N., Sazzad Hossain, Md. and Khan, M.N.I. (2020) Estimation of Structural, Electrical, and Magnetic Variations of Mn-Ni-Zn Ferrites by Substituting Rare Earth $\mathrm{Y}^{3+}$ for High-Frequency Applications. Journal of Superconductivity and Novel Magnetism, 33, 2133-2142.

https://doi.org/10.1007/s10948-020-05471-9

[43] Smit, J. and Wijn, H.P. (1959) Ferrites. John Wiley \& Sons, Pub. Co., Hoboken.

[44] Bellad, S.S. and Chougule, B.K. (2000) Composition and Frequency-Dependent Dielectric Properties of Li-Mg-Ti Ferrites. Materials Chemistry and Physics, 66, 58-63. https://doi.org/10.1016/S0254-0584(00)00273-X

[45] Prasad, M.S.R., Prasad, B.B.V.S. and Babu, B.R. (2015) Magnetic, Structural and Dc electrical Resistivity Studies on the Divalent Cobalt Substituted Ni-Zn Ferrite System. International Journal of Modern Physics B, 29, Article ID: 1550067. https://doi.org/10.1142/S0217979215500678

[46] Gabal, M.A., Al-Luhaibi, R.S. and Al Angari, Y.M. (2013) Effect of Zn-Substitution on the Structural and Magnetic Properties of Mn-Zn Ferrites Synthesized from Spent Zn-C Batteries. Journal of Magnetism and Magnetic Materials, 348, 107-112. https://doi.org/10.1016/j.jmmm.2013.08.002 